TRABAJO Y TRABAJADORES:

RED LATINOAMERICANA

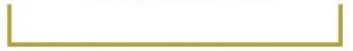

\title{
"Rebuscadores de residuos" a fines del siglo XIX: historia de una profesionalización inconclusa (Buenos Aires, 1870-1911)
}

\author{
SABINA DIMARCO \\ Consejo Nacional de Investigaciones Científicas y Técnicas \\ Universidad Nacional de General Sarmiento \\ sdimarco@,campus.ungs.edu.ar
}

\begin{abstract}
Resumen: Este artículo se ocupa del análisis del período de mayor desarrollo de la práctica de clasificación de residuos en Buenos Aires, Argentina, a fines del siglo XIX, período que se vio clausurado a comienzos del siglo XX. Nos interesa en particular abordar el modo ambivalente en que esa práctica laboral era representada socialmente en un momento en el que su valor económico no estaba puesto en duda. En particular, las dificultades que encontraron estos trabajadores para profesionalizarse hasta quedar desplazados de las ocupaciones laborales socialmente reconocidas a comienzos del siglo XX. De este modo, buscamos indagar en algunas claves interpretativas de la persistencia que a lo largo del tiempo ha tenido la imagen estigmatizante de los recuperadores de residuos; imagen que en la actualidad, a partir de las preocupaciones ambientales, se encuentra en plena disputa simbólica. El artículo se apoya en un corpus de fuentes heterogéneas que incluyen memorias y revistas municipales, prensa, registros policiales, obras de teatro, diarios de viajeros, fotografías y grabados, entre otras.
\end{abstract}

Palabras clave: recuperadores de residuos, trabajo, basura, residuos, Buenos Aires

Recibido: 1 de febrero de 2021 . Aprobado: 7 de mayo de 2021. 


\section{Introducción ${ }^{1}$}

“La Argentina de cartón”, titulaba el diario más leído del país en el año 2002 una nota sobre las consecuencias de la grave crisis económica, social y política que atravesaba la sociedad argentina por aquellos días. Los “cartoneros”, es decir, quienes vivían de la recuperación y venta de los materiales que rescataban de los desechos depositados en las calles, aparecían allí como símbolo de ese país en crisis. La nota describía su llegada cotidiana y masiva a la ciudad de Buenos Aires como una "invasión” de lo que llamaba "los ejércitos de las noches”; ejércitos compuestos por personas que llegaban desde el conurbano y desde los barrios pobres del sur de la ciudad de Buenos Aires, hacia los barrios porteños más pudientes, cuyo nivel socioeconómico alto se replicaba en los desechos producidos: desechos en mayor cantidad y de mejor "calidad" que los que se encontraban en otras zonas. La nota narraba con asombro que "unos 40 mil cartoneros invaden noche a noche Buenos Aires” y aclaraba: "Sólo una cuarta parte son cirujas clásicos. El resto perdió su trabajo o no consigue el primero. Y se larga a un oficio que se satura por exceso de mano de obra”. ${ }^{2}$

En esa nota aparecen mencionadas dos cuestiones que, en aquellos días, al calor de la crisis, se reproducían en los distintos medios de comunicación. Por un lado, el recurso a la imagen de la “invasión”, como modo de transmitir la sorpresa (y el temor) frente a un fenómeno que era visto y vivido como novedoso. Por el otro, la diferenciación entre los recuperadores de residuos anteriores y posteriores a la crisis. La popularización del término "cartoneros" que se produjo en ese momento -término que se utilizaba muy poco hasta entonces- reflejaba un cambio en las representaciones sociales respecto de estos trabajadores de los desechos. Desde los medios de comunicación, los estudios académicos y el saber popular, se comenzó a distinguir entre los "cirujas" de antes, figuras representadas como marginales y lindantes con la mendicidad, y los "cartoneros", trabajadores informales buscando ganarse la vida frente al desempleo creciente. Así, si bien la práctica en sí misma no era muy diferente en sus características esenciales, el modo en que se la percibía durante los años en los que la Argentina gozó de una suerte de "sociedad salarial" se distanciaba de la forma en que comenzó a pensársela en los años de su desmantelamiento y de creciente desempleo y precarización laboral. Si hasta entonces los "cirujas" aparecían en el

1 Agradezco las valiosas recomendaciones de quienes evaluaron este texto y también muy especialmente al Centro de Estudios Históricos de los Trabajadores y las Izquierdas (CEHTI) por facilitarme el acceso digital a parte de las fuentes que sostienen el argumento, en un contexto en el que las medidas restrictivas frente a la pandemia de COVID-19 imposibilitaron otras formas de acceder a materiales de archivo

2 Clarín, 27 de octubre de 2002. 
imaginario social como personas marginales que se mantenían por fuera de la relación salarial, la clasificación de residuos que llevaban adelante los "cartoneros" comenzó a ser vista como una actividad "refugio" de personas que en su mayoría provenían de un trabajo asalariado y se encontraban desempleadas. ${ }^{3}$ Pero la actividad de recuperación informal de residuos en Argentina, y en particular en Buenos Aires, se remonta a bastante antes de ese momento de desestructuración de las relaciones salariales (años noventa) e, incluso, de su momento de extensión y generalización (años cuarenta). Es más, lo que podríamos llamar el período de auge de la clasificación de residuos coincide con el momento de consolidación de un mercado de trabajo capitalista en el que la figura del trabajador asalariado formal recién se está constituyendo.

El presente artículo analiza ese período previo tanto de la emergencia de la figura del "ciruja" como de la del "cartonero". Se ocupa del análisis del momento de mayor desarrollo de la práctica de clasificación de residuos, a fines del siglo XIX, período que se vio clausurado a comienzos del siglo XX con la instauración de lo que en otros trabajos llamamos la "concepción patógena de los desechos" ${ }^{*}$ y la prohibición de esa práctica. Nos interesa fundamentalmente abordar el modo ambivalente en que la tarea de las y los recuperadores era representada socialmente en un momento en el que su valor económico no estaba puesto en duda. Y en particular, las dificultades que encontraron estos trabajadores para profesionalizarse hasta quedar, finalmente, desplazados de las ocupaciones laborales socialmente reconocidas a comienzos del siglo XX. De este modo, buscamos indagar en algunas claves interpretativas de la persistencia que a lo largo del tiempo ha tenido la imagen estigmatizante de los recuperadores de residuos; imagen que, en la actualidad, a partir de las preocupaciones ambientales, se encuentra en plena disputa simbólica.

3 Este tema lo hemos desarrollado en Sabina Dimarco, "Entre el trabajo y la basura: socio-historia de la clasificación informal de residuos en la ciudad de Buenos Aires (1870-2010)", (Tesis de Doctorado en Ciencias Sociales, FCSUBA, 2010), y "De cirujas a recuperadores urbanos. Apuntes sobre la configuración de la 'cuestión cartonera' en la ciudad de Buenos Aires”, en Reconfiguraciones del mundo popular. El conurbano bonaerense en la postconvertibilidad, coord. Maristella Svampa, Gabriel Kessler e Inés González Bombal (Buenos Aires: Biblos-UNGS, 2010).

4 Sabina Dimarco, "De lo patógeno a lo ambiental: disputas de sentido en torno a la clasificación de residuos", Revista Mexicana de Sociología, 74 (2012): 185-212; Sabina Dimarco, "Entre riesgo social y beneficio ambiental: transformaciones socio-históricas en la construcción social del riesgo de la clasificación de residuos", Quid 16, 2 (2012): 161-180. 
El artículo dialoga tanto con los estudios que abordaron la conformación de los inicios del mercado de trabajo "moderno" en Argentina ${ }^{5}$ como con las investigaciones locales, regionales e internacionales que se ocuparon de las actividades del "trabajo sucio" y, en particular, de la recuperación de residuos. ${ }^{6} \mathrm{Si}$ en el primer caso los recuperadores de residuos estuvieron prácticamente ausentes de los análisis, en los estudios específicos sobre este sector (que han proliferado en las últimas décadas) se le ha prestado muy poca atención a su historicidad. ${ }^{7}$ Nuestro trabajo busca entonces cubrir esa vacancia. Se nutre también de los aportes e interrogantes abiertos por la historiografía que desde hace ya varias décadas busca ampliar la mirada sobre la clase trabajadora, tradicionalmente asociada al trabajo industrial, formal y masculino, para preguntarse, justamente, por los procesos de configuración de la frontera - cambiante- entre trabajo y no-trabajo, que deja afuera a una variedad de formas de subsistencia. ${ }^{8}$ Estos estudios nos recuerdan la

$5 \quad$ Hilda Sábato y Luis Alberto Romero, Los trabajadores de Buenos Aires: la experiencia del mercado, 1850-1890 (Buenos Aires: Sudamericana, 1992); Ofelia Pianetto, "Mercado de trabajo y acción sindical. 1890-1922", Desarrollo Económico, 24, 94 (1984): 297-307; Ricardo Falcón, El mundo del trabajo urbano (1890-1914), (Buenos Aires: CEAL, 1986); Lucas Poy, Los orígenes de la clase obrera argentina. Huelgas, sociedades de resistencia y militancia política en Buenos Aires, 1880-1896, (Buenos Aires: Imago Mundi, 2014).

6 Dominique Lhuilier, "Le 'sale boulot”, Travailler, 14 (2005): 73-98; Jason Hughes, Ruth Simpson, et al., "Beyond the Symbolic: A Relational Approach to Dirty Work through a Study of Refuse Collectors and Street Cleaners", Work, Employment and Society, 31 (2017): 106-122; Martín Melosi, Garbage in the Cities. Refuse, Reform, and the Environment (Pittsburgh: University of Pittsburgh Press, 2005 [ $1^{\circ}$ ed.: 1947]); Martin Melosi, The Sanitary City, Environmental Services in Urban America from Colonial Times to Present (Pittsburgh: University of Pittsburgh Press, 2008); Susan Strasser, Waste and Want. A Social History of Trash (Nueva York: Metropolitan Books, 1999); Dominique Lhuilier y Yann Cochin, Des déchets et des hommes (Paris: Desclée De Brouwer, 1999); Catherine de Silguy, Histoire des hommes et de leurs ordures, du moyen-âge à nos jours (París: Le Cherche-Midi, 1996); Martín Medina, The World's Scavengers (Nueva York: Altamira Press, 2005); Ángel Prignano, Crónica de la basura porteña. Del fogón indígena al cinturón ecológico (Buenos Aires: Junta de Estudios Históricos de San José de Flores, 1998); Verónica Paiva, Cartoneros y cooperativas de recuperadores. Una mirada sobre la recolección informal (Buenos Aires: Prometeo, 2008); Francisco Suárez, La Reina del Plata. Buenos Aires: sociedad y residuos, (Buenos Aires: Ediciones UNGS, 2016); Pablo Schamber, De los desechos a las mercancías (Buenos Aires: SB, 2008), entre otros.

7 Algunas excepciones son los trabajos mencionados de Suárez (2016), Paiva (2008), Verónica Paiva y Mariano Perelman, “Aproximación histórica a la recolección formal e informal en la ciudad de Buenos Aires: La quema de Parque Patricios (1869-1917) y la del Bajo Flores (1920-1977)", Theomai, 21 (2010): 134-149.

8 Por mencionar solo algunos: Marcel van der Linden, Trabajadores y trabajadoras del mundo. Ensayos para una historia global del trabajo (Buenos Aires: Imago 
complejidad que encubre lo que parecen preguntas simples: ¿qué es el trabajo?, ${ }^{9}$ y ¿quiénes son los/as trabajadores? ${ }^{10}$

El artículo se inscribe en la perspectiva teórico-metodológica de la sociohistoria, ${ }^{11}$ cuyo propósito es indagar en la génesis de problemas sociales que en la actualidad forman parte de nuestra realidad cotidiana. Al poner de manifiesto la historicidad de los procesos que se nos presentan como "evidentes", la socio-historia, con su método regresivo, "remonta el curso naturalizador del tiempo". ${ }^{12}$ Entre sus principios metodológicos se cuentan: el ejercicio del asombro ante instituciones, rutinas y objetos con los que estamos familiarizados -analizándolos como el producto de procesos de larga duración que se fueron sedimentando o alteraron su significado-, la atención a las prácticas y dispositivos que habilitan ciertas formas de hacer, y el estudio de las formas de nominación y clasificación. ${ }^{13}$ Estos principios guían nuestras preguntas: ¿siempre la clasificación de residuos fue vista como una tarea degradante y problemática? ¿Qué la diferencia de otras actividades vinculadas a los desechos pero que sí forman parte de las actividades laborales formalizadas, reguladas, y socialmente legítimas? ¿De qué cambios más profundos nos hablan las derivas en las formas de nominación? Este trabajo intenta comenzar a responder algunas de estas preguntas.

Para ello nos apoyamos en un corpus documental variado y heterogéneo que busca atender tanto a las prácticas como a los discursos, así como reconstruir y abarcar una amplia diversidad de puntos de vista: memorias y revistas municipales, archivos policiales, diarios y revistas, ordenanzas municipales, registros fotográficos, informes de expertos, obras de teatro, órganos de difusión del Partido Socialista (La Vanguardia y El Obrero), entre otros.

En una primera parte, analizamos el modo en que a partir de las grandes epidemias acontecidas en las últimas décadas del siglo XIX fueron ganando importancia las actividades laborales vinculadas a la limpieza y la higiene de

Mundi, 2019); Fernanda Wanderley, “¿Qué es trabajo? Las fronteras conceptuales entre trabajo y no trabajo”, en Rossana Barragán Romano (comp.), Trabajos y Trabajadores en América Latina (Siglos XVI-XXI) (La Paz: CIS, 2019).

9 Mirta Zaida Lobato, Verena Stolcke, María Ullivarri, “Introducción”, en Rossana Barragán Romano (comp.), Trabajos y Trabajadores en América Latina (Siglos XVI-XXI) (La Paz: CIS, 2019).

10 Van der Linden, Trabajadores y trabajadoras del mundo.

11 Gerard Noiriel, Introduction á la socio-historie, (Paris: La Découverte, 2008); Michel Orffelé, "Socio-historie", en P. Perrineau y D. Reynié, Le dictionnaire du vote (Paris: PUF, 2001); Bénédicte Zimmermann, La constitution du chômage en Allemagne. Entre professions et territoires (Paris: MSH, 2001).

12 Philippe Corcuff, "Análisis político, historia y pluralización de los modelos de historicidad: Elementos de epistemología reflexiva”, Cultura y representaciones sociales, 6, 12 (2012): 38-74.

13 Orffelé, "Socio-histoire". 
la ciudad. En una segunda parte, nos ocupamos en particular de los trabajadores encargados de la clasificación y recuperación de residuos comercializables, indagando en las distintas modalidades que adquiría esa práctica a finales del siglo XIX. En un tercer momento estudiamos la forma en que eran percibidos por sus contemporáneos quienes se encargaban de esa tarea. Por último, analizamos las dificultades que encontró esta actividad para formalizarse hasta quedar, finalmente, relegada de las ocupaciones laborales social e institucionalmente reconocidas.

\section{Trabajadores de la limpieza pública en una Buenos Aires que se moderniza (1870-1910)}

El último cuarto del siglo XIX en Argentina estuvo atravesado por profundas transformaciones cuyo impacto fue particularmente notable en la ciudad de Buenos Aires. A partir del acelerado proceso de urbanización, y los cambios en la estructura productiva y el mercado laboral, Buenos Aires fue dejando atrás muchos de los rasgos que la habían caracterizado en el período colonial y que para entonces aún conservaba. En gran medida a causa de la llegada masiva de inmigrantes al país, en unas pocas décadas la ciudad conoció un crecimiento demográfico sin precedentes (pasando de 178.000 a 1.575 .800 habitantes entre 1869 y 1914) y a un incremento territorial sustancial (de los escasos $50 \mathrm{~km}^{2}$ que tenía en 1880 a $203 \mathrm{~km}^{2}$ con la incorporación de los territorios de Flores y Belgrano en 1887). En el lapso de cincuenta años la ciudad de Buenos Aires se transformó en una pujante metrópoli y una de las urbes más pobladas y de mayor extensión del mundo. ${ }^{14}$

En cuanto al mercado de trabajo, son años en los que comienzan a extenderse las relaciones salariales a expensas de las prácticas de trabajo autónomo y de autosubsistencia. Siguiendo las necesidades de un capitalismo periférico basado en la exportación de materias primas, el mercado laboral recibió un fuerte impulso con la llegada de inmigrantes en edad activa. De acuerdo con el Censo de 1887, la mitad de los habitantes de la ciudad de Buenos Aires eran extranjeros $(52,7 \%)$. La población ocupada pasó de 90 mil personas aproximadamente- a más de 1 millón entre 1869 y 1914. Junto al alto porcentaje de población inmigrante (cerca del $70 \%$ de la población trabajadora), estaban también las y los trabajadores oriundos de la ciudad o de la campaña bonaerense y provenientes de otras provincias o de los

14 James Scobie, Buenos Aires, del centro a los barrios. 1870-1910 (Buenos Aires: Ediciones Solar, 1986 [1 $1^{\circ}$ ed.: 1977]); Matías Landau, Gobernar Buenos Aires. Ciudad, política y sociedad, del siglo XIX a nuestros días (Buenos Aires: Prometeo, 2018). 
territorios nacionales. A pesar del peso de la población masculina entre la población ocupada, el trabajo femenino era significativo. ${ }^{15}$

Tanto en el caso de los varones como de las mujeres los censos y archivos dan cuenta de una gran diversidad de ocupaciones. Una proporción muy considerable se empleaba en establecimientos industriales y manufactureros, y el sector de la construcción se vio particularmente alentado por el dinamismo del crecimiento urbano. El impulso de esta rama de actividad estaba relacionado con la extensión de servicios públicos que serían esenciales en esos años, tales como agua corriente, cloacas, escuelas, pavimentos, alumbrado, etc., y la construcción de grandes edificios que se volverían icónicos como el Teatro Colón, el Congreso o el Palacio de Correos, entre otros. Destacaba también por su número la población empleada en el ámbito del comercio, tanto en los establecimientos comerciales (dueños o empleados) como en casas particulares como "domésticos". Los trabajadores vinculados a la actividad de transporte constituían otro sector numeroso: destacaban los cocheros y carreros, marinos, changadores y empleados ferroviarios. A su vez, en el marco de la consolidación y expansión estatal, vale mencionar el notable incremento de los trabajadores de la "administración pública" (empleados de gobierno o administración) que pasaron de casi 10 mil personas a más de 49 mil entre 1895 y 1914.

En los censos de aquellos años, las categorías de "jornaleros" y "peones" aparecen particularmente nutridas, sumando algo más de 28 mil personas en 1895, mientras que "sin profesión" contaba para ese año con 150 mil personas (un $32 \%$ de la población de aquel entonces). Estas categorías en su conjunto nos muestran otra característica del mercado laboral de la época: la alta inestabilidad del empleo, muy relacionada con la estructura productiva agroexportadora dependiente, y su contracara, el empleo ocasional e intermitente, la pluri-ocupación, la alta movilidad, y la alternancia entre períodos con trabajo y sin éste. ${ }^{16}$

En ese amplio abanico de oficios y ocupaciones que se desplegaban en la Buenos Aires de entre siglos, empezaron a incrementarse las actividades laborales vinculadas a la limpieza urbana y, entre ellas, las relacionadas a la recolección y tratamiento de desechos. En efecto, acompañando ese pujante desarrollo urbano, comenzó a tener cada vez más centralidad el problema de la higiene pública y los desechos urbanos. Con el incremento poblacional, la

15 Paula Aguilar, El hogar como problema y como solución (Buenos Aires: Ediciones CCC, 2014); Graciela Queirolo, "El trabajo femenino en la ciudad de Buenos Aires. Una revisión historiográfica (1890-1940), Tema de mujeres, 1, 1 (2004): 55-87.

16 Sábato y Romero, Los trabajadores de Buenos Aires; Pianetto, "Mercado de trabajo". 
producción industrial en marcha y los cambios en los hábitos de consumo, aumentó de modo considerable la producción de desechos urbanos.

Las crónicas de la época transmiten la imagen de una ciudad colmada de toda clase de desperdicios, desde residuos domésticos y desechos fecales a cuerpos de animales muertos y gran cantidad de bosta de caballo por la tracción a sangre que se utilizaba como medio de transporte. A la acumulación de desechos en las calles se agregaba la falta de un sistema de desagüe y el frecuente desborde de los excusados. ${ }^{17}$ Algunos relatos mencionan que durante el verano ciertas zonas podían volverse intransitables a causa del olor nauseabundo que desprendían los desechos. Sin embargo, hasta la llegada de las epidemias de cólera (1867-1868) y fiebre amarilla (1871) y sus dramáticas consecuencias, la higiene, y los desechos en particular, no constituyeron un tema de preocupación para las autoridades públicas ni para la población en general. Hasta ese momento, la higiene y la limpieza habían sido responsabilidad individual. ${ }^{18}$ Tal como han señalado investigaciones de otros países, hasta bien entrado el siglo XIX las responsabilidades de los gobiernos sobre la higiene y la gestión de los desechos era muy menor y correspondía a los habitantes de las ciudades ocuparse de deshacerse de sus propios restos de la forma que le resultara más accesible. ${ }^{19}$ Los habitantes de Buenos Aires recurrían por lo general a enterrarlos en los fondos de las casas particulares y a arrojarlos a las calles o a los numerosos terrenos baldíos que todavía quedaban en la ciudad. ${ }^{20}$ Esa forma de manejarse no había causado hasta el momento más que preocupaciones de tipo estético, o vinculadas a las dificultades que causaban en el tránsito. Pero frente al desencadenamiento de aquellas epidemias - particularmente la de fiebre amarilla con un saldo de muertes cercano al $8 \%$ de la población porteña-, y ante el desconocimiento de las causas que la provocaban, la atención se centró en la higiene urbana y, con ella, en los desechos.

Promovidas en gran medida por la perspectiva miasmática de la enfermedad aportada por los médicos higienistas, se pusieron en marcha una serie de intervenciones orientadas a mejorar la limpieza, la higiene pública y la circulación del aire; por ejemplo, la instalación de una red de agua potable, la construcción de un sistema de desagüe cloacal, la creación de parques y plazas y el ensanchamiento de avenidas. En ese marco, la gestión y el tratamiento de los desechos dejó de ser un tema de índole individual para adquirir el estatus de problema de salud pública.

17 Scobie, Buenos Aires, 71.

18 Sabina Dimarco, “De la 'ciudad higiénica' a la 'ciudad sustentable', Ciudades, 91 (2011).

19 Melosi, Garbage in the Cities.

20 Prignano, Crónica de la basura; Suárez, La Reina del Plata. 
En 1871, una ordenanza declaró obligatorio para los vecinos porteños el aseo de los frentes de las casas, mientras que la Municipalidad se encargaba del barrido de una acotada zona céntrica ${ }^{21}$ de la que se ocupaban unos sesenta peones provistos de escoba, pala, regadera y carretilla de mano. ${ }^{22}$ A partir de 1881 comenzó a organizarse un servicio más amplio de barrenderos públicos, primero a modo de ensayo con un pequeño número, hasta llegar a algo más de cuatrocientos trabajadores en 1887. A cada barrendero se le adjudicaba una determinada cantidad de cuadras que atender y se procuraba contar con personal estable. Torcuato de Alvear, cuya administración como primer intendente de la Buenos Aires federalizada pasaría a la historia como arquetipo de una gestión racional y moderna, ${ }^{23}$ declaraba: “(...) se ha llegado a conseguir un aseo constante, si no perfecto muy regular", ${ }^{24} \mathrm{y}$ presentaba las cifras de trabajadores y la regularidad que había adquirido el servicio como muestra indiscutible de progreso. En 1885 se ensayó por primera vez la limpieza de las calles utilizando máquinas barredoras que imitaban el modelo francés y se dio comienzo al barrido regular a cargo de la Municipalidad. ${ }^{25}$

De este modo, en esas últimas décadas del siglo XIX, acompañando la formación de un Estado moderno con sus requerimientos de personal, se fue estableciendo en Buenos Aires un servicio de limpieza pública que dio lugar, a su vez, a una serie de nuevos puestos laborales vinculados a esa área. Las memorias municipales dejan constancia de que no era un servicio más sino uno de los que mayor presupuesto requería. Gran parte de ese presupuesto se explicaba por la cantidad de personal que empleaba; en el censo de la ciudad de 1887 se hablaba de "un verdadero ejército de operadores, compuesto de 1134 plazas". ${ }^{26}$ Entre estos trabajadores de la limpieza pública se encontraban, además de los barrenderos (tanto los encargados de las máquinas barredoras como los barrenderos que, dotados de pala y escoba, se encargaban de las calles a las que no llegaban las máquinas), los basureros y los carreros. Los basureros eran los responsables de retirar los recipientes domiciliarios de desechos de las casas -al comienzo, y luego desde las veredas y zaguanes cuando se impuso esa costumbre-, volcar su contenido en su propio recipiente y, de allí, al carro manejado por el carrero. Estos últimos eran quienes también transportaban los desechos hasta el sitio de descarga:

21 Área comprendida entre las calles Balcarce, 25 de Mayo, Uruguay-San José, Charcas e Independencia. (Prignano, Crónica de la basura).

22 Censo Municipal de Buenos Aires, 1887, p. 232.

23 Adrián Gorelik, La grilla y el parque: espacio público y cultura urbana en Buenos Aires, 1887-1936 (Buenos Aires: Universidad Nacional de Quilmes, 1998).

24. Adrián Beccar Varela, Torcuato de Alvear. Primer intendente municipal de la ciudad de Buenos Aires. Su acción edilicia (Buenos Aires: Kraft, 1926).

25 Censo General de Población, Edificación, Comercio e Industrias de la Ciudad de Buenos Aires, 1887, p. 232.

26 Ibid. 
el vaciadero. Estos trabajadores se fueron volviendo cada vez más imprescindibles para el aseo de la ciudad, lo que les daba fuerza para llevar adelante huelgas que, al decir de los socialistas de El Obrero, dejaban las calles “convertidas en depósitos de basura”. ${ }^{27}$ La primera huelga de peones municipales vinculados a la limpieza urbana es, de hecho, muy temprana: se lleva a cabo en 1876 y pone de manifiesto las duras condiciones laborales que atravesaba el sector ya que fue impulsada porque llevaban dieciséis meses sin cobrar sus salarios.28 A ello se sumaban las largas jornadas laborales, el trabajo pesado, y la falta de tiempos de descanso.

En esta lista de trabajadores del aseo urbano debemos incluir también a los encargados de los carros de riego, tarea que se realizaba antes del paso de los barrenderos para asentar el polvo de las calles. Y a partir de la implementación de la red cloacal, también los cloaqueros podrían entrar en esta enumeración. En efecto, con la instalación de cloacas surgieron nuevos problemas como las obstrucciones de cañerías, y con ellos, la aparición de "limpiadores de cloacas" o "cloaqueros". ${ }^{29}$ Entre 1886 y 1890, se incorporó también un contingente de peones encargados de recoger a pie, durante el día, los desechos que ensuciaban las calles centrales. El censo de 1887 los nombra como traperos. El uso de este término es interesante puesto que responde a una traducción literal del vocablo francés "chiffonniers", que nombra en el país galo a los clasificadores de residuos de ese mismo período histórico y que se explica porque los trapos -junto con los huesosconstituían el principal material recuperado en tanto era una materia prima fundamental para la vital industria del papel. ${ }^{30}$ En el caso de la ciudad de Buenos Aires, en cambio, el término aparecía utilizado para identificar a esos trabajadores de la limpieza contratados por la municipalidad para levantar los desperdicios, papeles principalmente, valiéndose de escoba y canasta. En 1890, con el barrido nocturno regularizado, la municipalidad prescindió de estos trabajadores y los reemplazó por otros encargados únicamente de recoger el estiércol de las calles más transitadas. ${ }^{31} \mathrm{El}$ periódico socialista La Vanguardia mencionaba en 1897 a estos trabajadores remarcando el carácter degradante de su labor:

Estos hombres pasan su vida en ese trabajo por cuarenta y nueve pesos por mes. Han aparecido en las calles de Buenos Aires, desde que muchas de estas están adoquinadas de madera, para que rueden mejor los carruajes de los ricos. Se les ve en la avenida de Mayo y en la avenida Alvear, recogiendo el

\footnotetext{
27 El Obrero, 12/02/1893.

28 Prignano, Crónica de la basura.

29 Prignano, Crónica de la basura.

so De Silguy, Histoire des hommes; Sabine Barles, L'invention des déchets urbains.

France: 1790-1970 (Paris: Champ-Vallon, 2005).

31 Memoria Municipal, 1890.
} 
estiércol de los caballos de los coches, y echándolo al canasto que llevan a la espalda. ${ }^{32}$

La materialidad del desecho (papeles vs. estiércol) evidencia sus efectos en la valoración de la actividad. ${ }^{33}$

El trabajo de los barrenderos - como el del resto de los trabajadores de la limpieza- se encontraba en una posición subordinada en la jerarquía ocupacional. Un ejemplo interesante de esa posición casi lindante con la marginalidad es la denuncia que en 1892 realizaban los socialistas de $E l$ Obrero, que acusaban a la municipalidad de utilizar para esas tareas a personas apresadas por el delito de "vagancia". En ciertas ocasiones, devenir barrendero público era entonces un castigo: "El Intendente municipal Sr. Bollini ha determinado y resuelto: [...] Que los vagos se ocuparán en la faena de barrido, quedando de la incumbencia de la comisión de cárceles de hospedar y alimentar a estos prisioneros". La paradoja, planteaban los socialistas, era que los barrenderos contratados - que se encontraban impagos desde hacía varios meses- "se echarán a la calle" y se convertirían ellos mismos en personas acusadas de vagancia y obligados a trabajos públicos. ${ }^{34}$

Los desperdicios recogidos con el barrido de calles y la recolección de desechos domiciliarios eran trasportados al vaciadero municipal. Desde allí un ramal del Ferrocarril Oeste, denominado popularmente como el "tren de las basuras", ${ }^{35}$ los trasladaba hasta su último destino: el predio conocido como "la Quema", ubicado en las afueras de la ciudad. La Quema se llamaba tanto al sistema como al lugar físico implementado oficialmente en 1871 (aunque ya funcionaba de hecho) para la eliminación de los desechos urbanos. Al encontrarse ubicado -en un principio- fuera de los límites de la ciudad, el tren cumplía un papel fundamental en la expulsión hacia el exterior urbano de los desperdicios producidos en la urbe siguiendo la lógica de "fuera de la vista, fuera de la mente". ${ }^{36}$ Poco después, se produjo el doble proceso de clausura del vaciadero (ubicado en un espacio demasiado céntrico ${ }^{37}$ ) y la incorporación de la Quema a la jurisdicción de la ciudad con el ensanche municipal de 1887. Con el cierre del vaciadero y la desactivación en 1888 del ramal del ferrocarril destinado al transporte de desechos, los carreros debieron extender su recorrido hasta la misma Quema. ${ }^{38}$ Prignano señala

32 La Vanguardia, 7/8/1897.

33 Hughes et al., "Beyond the Symbolic".

34 El Obrero, 5/3/1982.

35 Este ramal del Ferrocarril Oeste fue oficialmente inaugurado en 1873.

36 Melosi, Garbage in the Cities. La traducción es nuestra.

37 Hacia 1880 la prensa dejó constancia de los reclamos de los vecinos porteños para que se cierre el vaciadero municipal.

38 Luis Cortese, "Un tren entre las basuras y el vaciadero", Historias de la ciudad. Una revista de Buenos Aires, 9 (2001); Prignano, Crónica de la basura. 
que, en el intento de disminuir la cantidad de viajes realizados, los carros iban colmados haciendo el viaje bastante difícil a causa del olor de los desechos en descomposición.

Al comienzo, la Quema funcionaba como mero reservorio de desechos a la espera de su desintegración. Pero su rápida acumulación, con la consecuente emanación de olores nauseabundos, la convirtieron en una gran preocupación en el marco de la epidemia de fiebre amarilla y el temor a los "miasmas". Por eso la propuesta de un sistema de incineración a implementarse allí mismo, presentada por un ex inspector municipal de apellido Borches, fue recibida como un gran adelanto para la salud pública. ${ }^{39} \mathrm{El}$ "sistema Borches" era sencillo: consistía en quemar al aire libre esos desechos ubicándolos en unas "hornallas" o "parrillas", construidas de modo rudimentario con "tachos, latas y fierros viejos que han ido cayendo en el entrevero". ${ }^{40}$ Los carros que llegaban con su carga de desechos dejaban "escurrir viscosamente su contenido" sobre las parrillas. ${ }^{41}$

Pero lo que nos interesa particularmente es que con la implementación de este sistema se dio comienzo a una práctica de la que en ese entonces se resaltaban sus considerables beneficios económicos: la "extracción de residuos entre las basuras". ${ }^{42}$ Consistía en la clasificación y separación de los materiales que pudiesen tener algún valor económico (o de uso) potencial antes de volcar los desechos restantes a las hornallas de incineración para su eliminación final. Tal como ocurría con otros servicios de higiene urbana de la época, este adoptó la forma de una gestión descentralizada-privada (responsabilidad municipal, pero concesión a empresas privadas). ${ }^{43}$ Diferentes actores se disputaron desde entonces ese "derecho de extracción" por el que pagaban un canon a la Municipalidad. Las empresas que accedían a la concesión tenían derecho a "extraer de las basuras los residuos reutilizables como huesos, fierro y otros metales, trapos, vidrio, ceniza, etc." ${ }^{44}$ diferenciando así "residuos", entendidos como todo aquello que podía tener un valor económico, de "basura" como el resto último.

Los trabajadores de la Quema eran entonces el otro gran componente de los trabajadores de la limpieza urbana de la ciudad.

39 Prignano, Crónica de la basura.

40 Caras y Caretas, 16 (1899): 18.

41 Ibíd.

42 Término utilizado en las Memorias Municipales en las licitaciones de este servicio.

43 Pedro Pírez, "Gestión de servicios y calidad urbana en la ciudad de Buenos Aires”, Eure, 25 (1999).

44. Memoria Municipal, 1876. 


\section{La extracción de residuos como práctica laboral: los primeros recuperadores de Buenos Aires (1870-1900)}

Si bien no en los mismos niveles en que se dio en los países de industrialización más temprana, los residuos ocuparon en Argentina un rol considerable como materias primas en el despuntar de la industria local. La práctica de "extracción de residuos entre los desechos" que se desarrolló en el espacio de la Quema durante las últimas cuatro décadas del siglo XIX establecía una diferencia entre "residuos", como elementos valorizables, y "basura”, como aquello que quedaba luego de extraído lo que pudiese tener algún valor comercial. Los usos que encontraban esos residuos recuperados estaban, por supuesto, relacionados con las prácticas, los consumos y los desarrollos técnicos e industriales de la época. A fines del siglo XIX, el célebre médico higienista Eduardo Wilde sostenía que la separación de "las partes utilizables" de la basura "es de suma conveniencia para la industria y para la higiene. (...) Tiene además abonos que la agricultura puede aprovechar" ${ }^{45}$

La industria naciente se convirtió en una consumidora importante de los materiales recuperados. La industria papelera, que en países como Francia y Estados Unidos fue el motor del desarrollo de la práctica de recuperación de residuos como trapos viejos y restos de papel usado, comenzó a desarrollarse en Argentina hacia 1880. Hasta entonces, el papel se importaba en su totalidad. Para 1914 se encontraban funcionando once fábricas de papel y cartón, pero como la producción local se desarrollaba menos dinámicamente que las necesidades, la importación siguió siendo considerable. De los distintos tipos de papeles que circulaban en el país, el papel para envolver era el de mayor producción local, y utilizaba un componente importante de materiales recuperados, en particular trapos y papeles viejos. De todos modos, la producción local nunca llegó a tener la envergadura necesaria para motorizar la actividad del reciclado como en aquellos otros países mencionados y tempranamente, hacia 1889, comenzó la importación de pasta celulosa que desplazó en parte la necesidad de esas materias primas recuperadas. ${ }^{46}$ Aun así, la recuperación de residuos tuvo en estas décadas de fin de siglo un importante impulso.

La industria del papel no era la única que recurría a materiales recuperados de la Quema. Esos materiales llegaban a las industrias en bolsas transportadas por carros luego de haberse realizado la clasificación. Prignano

45 Año 1885. Citado en Suárez, La reina del Plata.

46 Sobre la industria del papel en Argentina ver José Luis Irigoyen, La industria del papel en la República Argentina (Tesis de doctorado en Ciencias Económicas, UBA, 1941). 
y Schamber mencionan la existencia de galpones en los alrededores mismos de la quema y de carros que pasaban regularmente a comprar el material. ${ }^{47}$

Otros usos que se le daba a los materiales recuperados eran, por un lado, de tipo agrario y, por el otro, para diferentes necesidades relativas a la vida urbana. En 1887, por ejemplo, la municipalidad firmó un contrato con dos particulares para la elaboración de huano $^{48}$ con la sangre resultante de la faena diaria en el nuevo Matadero; ello permitía, a su vez, reducir ese residuo tan particular, cuya extracción ocasionaba altos gastos a la Municipalidad. ${ }^{49}$ El aceite de potro, resultado también del trabajo en los saladeros, se utilizó durante varios años para iluminar las calles de la ciudad ${ }^{50}$ y las latas eran utilizadas, entre otras cosas, para la obtención de estaño. ${ }^{51}$ Hasta las pieles de gatos y perros muertos eran reutilizadas: “después de estaqueadas, pasan a ser quillangos las gatunas y botines y carteras las perrunas". ${ }^{52}$ Además, los residuos cumplieron un papel fundamental tanto en el relleno de terrenos bajos en el marco del proceso de urbanización como en la pavimentación de las calles céntricas.

Entre quienes se beneficiaban de esa extracción de residuos se encontraban los sectores industriales que los incorporaban a su producción, la Municipalidad que cobraba por ese servicio, el contratista que la tenía a cargo, y los trabajadores y trabajadoras que encontraban allí una fuente de ingresos. Entre estos últimos, a su vez, estaban quienes trabajaban para el contratista a cambio de un jornal y quienes lo hacían por su cuenta y luego vendían lo recolectado en los depósitos de comercialización que, como vimos, fueron surgiendo en los alrededores de la Quema. Y además de las personas que recuperaban residuos en la Quema, estaban quienes lo hacían recorriendo las calles de forma independiente.

47 Ángel Prignano, "El bañado de Flores en el siglo XX”, en El Buenos Aires de Enrique Horacio Puccia (1910-1995), comp. Alberto Piñeiro (Buenos Aires:

Comisión para la Preservación del Patrimonio Histórico Cultural de la ciudad de Buenos Aires, 2005); Schamber, De los desechos.

48 De este modo aparece mencionado en el informe. Se refiere al guano, término utilizado para referir a la materia orgánica en descomposición, principalmente de excrementos animales (estiércol), con fines de abono agrícola.

49 Memoria Municipal, 1877.

50 Alfredo Irigoin, "La evolución industrial en Argentina", 1984. Disponible en línea: wrw.eseade.edu.ar/servicios/Libertas/49_6_Irigoin.pdf.

51 La Nación, 23/03/1915. Sobre la considerable cantidad de latas que conformaban la estructura de los desechos, un informe municipal del año 1904 hacía la siguiente apreciación: "Otro rasgo interesante de la composición mecánica de nuestras basuras es (...) la gran proporción de latas de envase de aceite y conserva alimenticias que contiene", Tratamiento y eliminación de las basuras. Informe teórico-práctico de la comisión especial, 1904: 326.

52 La Prensa, 21/6/1885. Citado en Prignano, Crónica de la basura:190-191. 
Si bien efectivamente había diferentes maneras de ejercer la clasificación de residuos en ese fin de siglo, lo cierto es que muchas veces solían ser las mismas personas las que alternaban y combinaban estas formas de llevar adelante esa actividad económica. A su vez, en un período en el que los empleos ocasionales y de corta duración empujaban con frecuencia a la pluriocupación, no podemos descartar que la recuperación de residuos haya sido una opción entre otras en tiempos en que mermaban las oportunidades en otros empleos rurales o urbanos. En efecto, algunas notas de los periódicos socialistas señalan que con frecuencia quienes se dedicaban a la recuperación de residuos formaban parte de esa heterogénea clase trabajadora que, en un mercado laboral caracterizado por la inestabilidad, experimentaba con frecuencia períodos en los que el empleo escaseaba y las opciones se reducían: en esos casos, la recuperación de residuos se presentaba como una posibilidad. ${ }^{53}$ Por eso no es de extrañar que en períodos de mayor oferta de empleos o en los que los sueldos abonados en la quema bajaban, la cantidad de trabajadores dispuestos a esa tarea mermara, mientras que en períodos de crisis y desempleo se incrementara no solo allí sino también en las calles porteñas. En este sentido, resulta poco pertinente la distinción formal/informal o asalariado/independiente.

Según la descripción de la Revista Municipal de 1895, en la Quema trabajaban parveros y peones encargados de la descarga de los carros y de separar los materiales que pudiesen tener algún valor industrial o de reventa. Los desechos que quedaban por fuera de su selección pasaban a ser consumidos por el fuego, tarea a cargo de los parveros. Estos se valían de rastrillos para depositar las basuras en los hornos y controlaban el proceso de cremación directamente parados sobre las montañas de desechos ardientes. Estos trabajadores formaban parte, entonces, del conjunto más amplio de personal vinculado a las tareas de limpieza pública. La cantidad de trabajadores que se ocupaban de estas faenas fue cambiando en las últimas décadas del siglo, pero su número oscilaba entre sesenta y cien. El informe del censo de 1887 menciona que había "un personal diario de 90 hombres encargados del trabajo de (...) aprovechar todos los productos aprovechables de las basuras", mientras que la Revista Municipal de 1895 da cuenta de unas sesenta y cinco personas divididas entre parveros y peones de clasificación. Los cambios en el número de peones contratados se explican, según las memorias municipales, por lo difícil que resultaba conseguir personas dispuestas a aceptar esa tarea dadas las insalubres condiciones laborales, el gran esfuerzo físico requerido y los magros salarios abonados. Desde el momento en que comenzó a concesionarse el derecho de extracción de

53 Sabina Dimarco, "Nociones de trabajo y desocupación en la prensa socialista de fines del siglo XIX”, Archivos de historia del movimiento obrero y la izquierda, 14 (2019): 97-118. 
residuos, la remuneración a los trabajadores de la Quema quedó a cargo del empresario que tenía la concesión. La Vanguardia denunciaba que el pago había empeorado notablemente desde entonces, al tiempo que a los trabajadores se les obligaba a trabajar más horas (pasando de 10 a 12 e incluso 14 horas de trabajo) y les cobraban multas si no alcanzaban los objetivos. ${ }^{54}$ Mencionaban también las duras condiciones laborales y los riesgos a los que se exponían.

Además de los trabajadores que recuperaban residuos por un jornal en el predio de la quema, había un grupo considerable de recuperadores que buscaban algo que todavía pudiese tener algún valor entre los desechos que habían sido descartados luego de una primera clasificación. Sin embargo, en los registros que han quedado del trabajo en la Quema resulta difícil -sino imposible- distinguir cuándo se está hablando de los clasificadores contratados y cuándo de los independientes ya que los equiparaba un similar grado de precariedad en la labor.

La revista Caras y Caretas de 1899 menciona a "unos cuantos hombres barbudos o lampiños, blancos o cobrizos, pero todos con un lustre sebáceo y un olor profesional" y describe dos etapas diferentes en la tarea de recuperación de residuos. La primera, hecha

á la gruesa y sin demora, porque la montaña arde por dentro y caldea los pies de los cateadores, que tosen y pernean como hirsutos demonios entre la humareda grasienta y cálida que sale á bocanadas por los intersticios de la parva y los ciega y atosiga, seguida á veces por alguna llamarada traicionera que saca la lengua de pronto y chamusca barbas y andrajos grasientos.

Luego de este rápido “cateo”, se pasaba a la segunda etapa de clasificación de la que se ocupaba "otro personal”. Mientras que la primera, de alto riesgo, era una selección grosso modo, en la segunda tenía lugar una separación más minuciosa según tipo (o clase) de material:

apartándose los trapos de hilo, los de algodón, los de seda, los paños de grana, las franjas de ropa militar, cada clase en su montón respectivo. Los vidrios reciben así mismo vanas clasificaciones; primero, de rotos y enteros; después, en la clase de enteros, de botellas y frascos, y luego, en estas divisiones, de la frágil especie de cada cual; botellas de bitter, de aperital, de fernet, de vermouth. de champagne, de hesperidina, ó bien frascos de botica, y entre éstos, los especiales de remedios conocidos: de zarzaparrilla, de emulsión, de gránulos, de glóbulos, de los mil jaropes milagrosos que diariamente da de sí la inagotable farmacopea industrial. Los vidrios rotos, que vienen á pagarlos las fábricas del ramo, se separan en vidrio blanco,

54 La Vanguardia, 6/3/1897. 
verde y azul, formando en pocos días verdaderos himalayas erizados de aristas agresivas, que relucen al sol”. ${ }^{55}$

Ese mismo artículo describe los alrededores de la quema, en donde se habían construido casillas con los materiales obtenidos en las basuras, dando lugar al célebre "barrio de las Ranas", mencionado por Guevara como la primera "villa miseria". ${ }^{56}$ Algunas crónicas preferían llamarlo "pueblo" por la distancia (física y moral, según veremos) que lo separaba de la trama urbana. En ese sitio, decía el artículo, "más de tres mil almas viven de la basura, asilo generoso de la pobreza inútil”. En este caso, los desechos proveían también la subsistencia pero en la nota aparecían diferenciados del personal mencionado anteriormente. Los "cateadores", como se llamaba a los trabajadores contratados, incluso en su extrema pobreza (como expresa esa descripción de las "barbas chamuscadas y andrajos grasientos") aparecen en el texto identificados como trabajadores, con una labor productiva, frente a la "pobreza inútil" de los "raneros".

Si bien es difícil rastrear la presencia de trabajadoras mujeres en los archivos (mucho más cuando se trata de sectores populares), en gran medida por el uso del masculino genérico, algunas crónicas, y fundamentalmente las fotografías, nos permiten identificar a una buena cantidad de mujeres entre los clasificadores de residuos. Probablemente las mujeres que se observan entre los desechos buscando residuos valorizables no pertenecían a los trabajadores contratados que, según se desprende de las memorias municipales, debían ser en su totalidad varones. Sin embargo, al observar las fotografías del trabajo en la Quema es evidente que las mujeres constituían un porcentaje considerable de esa fuerza de trabajo. En los registros fotográficos se las ve volcadas sobre los carros acompañando el deslizamiento de los detritus, y entre las montañas de basura con sus polleras y pañuelos atados en la cabeza, pero también se las observa descansando, riendo y tomando mate en las casillas del barrio de "las Ranas".

55 Caras y Caretas, $16(21 / 1 / 1899)$.

56 Celia Guevara, "Pobreza y marginación: el Barrio de las Ranas, 1887-1917", en Buenos Aires 1910: el imaginario para una gran capital, comp. Margarita Gutman y Thomas Reese (Buenos Aires: Eudeba, 1999). 


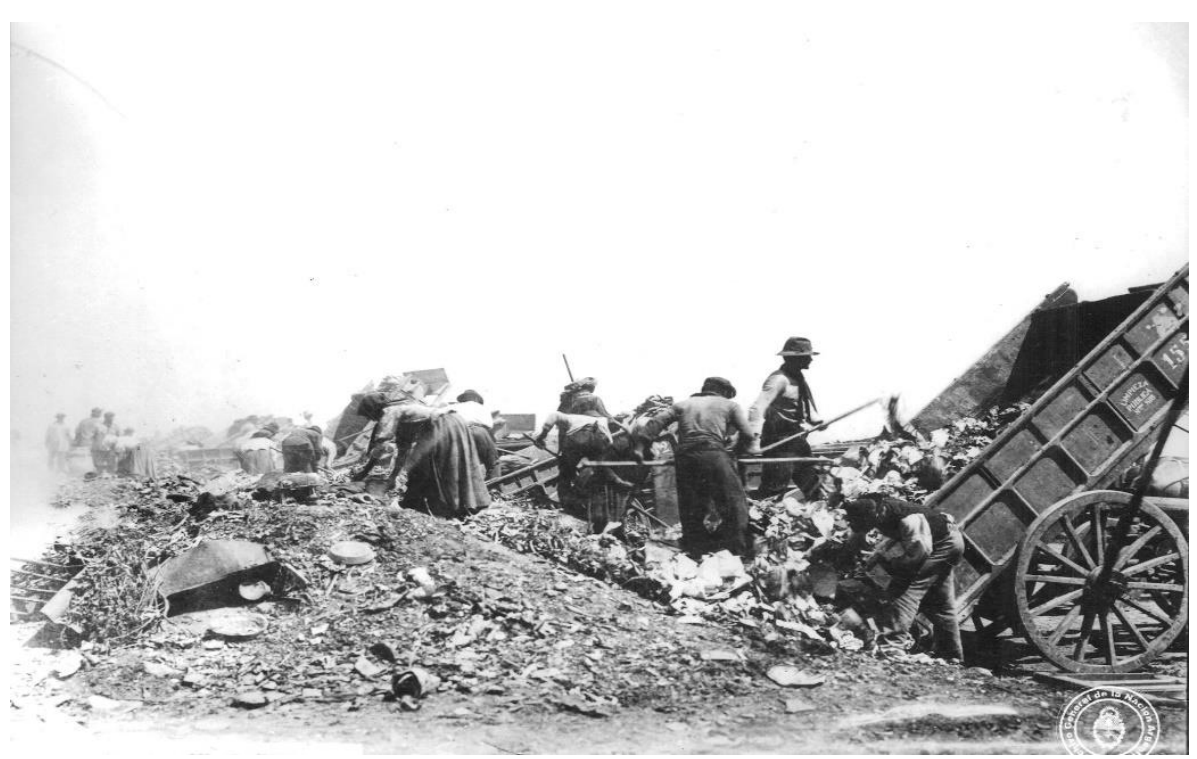

Descarga de desechos en la Quema, Archivo General de la Nación.

Los niños participaban también activamente de la clasificación. ${ }^{57}$ Un informe de 1904 describía así esta tarea:

Este campo de la quema está cruzado por una calle tortuosa y empedrada de más o menos un kilómetro de extensión á cuyos bordes depositan la basura los carros de la limpieza y aquí comienza la primera faena á que se la somete, de carácter puramente industrial: centenares de hombres, mujeres y niños de aspecto miserable, revuelven los montones de basuras para separar los materiales explotables. ${ }^{58}$

La Vanguardia menciona que la recuperación de residuos hecha por niños era una práctica que podía ayudar en los hogares pobres y con la que éstos contaban, incluso, como una opción menos denigrante que otras: "Saben ellas (las mujeres pobres y obreras) que sus hijos pueden ganar diez centavos por bolsas de huesos recolectados en la basura y prefieren ellas tener este dinero, cuando estarán enfermas, que á los dos centavos que dará cada señora, sobre cuatro pesos que cuestan sus guantes”. 59

Por otra parte, por comentarios como la piel "cobriza” de algunos/as recuperadores, y las fotos que han quedado como testimonio, es posible advertir que había una marcada heterogeneidad étnica y racial, con un importante componente mestizo y afrodescendiente. Es posible entonces que,

57 Por el momento no hemos podido identificar si las niñas también participaban.

58 Tratamiento y eliminación, 18.

$59 \quad$ La Vanguardia, 27/7/1901. 
en el modo en que era percibida esta actividad, y en particular en lo relativo a las percepciones "alterizantes" que analizaremos más adelante, jugasen también cuestiones vinculadas a la identidad racializada de estos/as trabajadores. ${ }^{60}$

El predio de la Quema no era el único sitio en el que se realizaba la clasificación de residuos en estos años de fin de siglo. También se llevaba adelante en la vía pública, hurgando en las cajas y canastas que contenían los desechos o comprándolos por escaso monto a vecinos y comerciantes para revenderlos a un precio mejor en las fábricas. Por lo general, la clasificación de residuos en las calles se vinculaba a situaciones de pobreza extrema. En esas ocasiones la búsqueda de alimentos era un componente importante, pero no era el único. Sin embargo, la insistencia de ciertos relatos de la época en la asociación de la recuperación a la búsqueda de alimentos, y generalizarla, era una forma, como veremos luego, de desestimar la labor productiva de estos/as trabajadores de los desechos.

La memoria municipal de 1877 consigna que para ese año los ingresos que percibían los contratistas habían bajado a la mitad del año anterior y la autoridades municipales -que vieron en consecuencia afectados los ingresos que recibían por esa concesión- atribuyeron la causa principal al "gran número de individuos que recorren las calles extrayendo de los cajones que deposita el vecindario en las puertas de las casas, todos los residuos utilizables, de suerte que cuando llegan los carros al vaciadero, ha sido ya despojada la basura de la mayor parte de ellos" ${ }^{61}$ Para evitarlo, recurrieron a la intervención policial para prohibir a los "rebuscadores de residuos el extraerlos de los depósitos en que los colocan los vecinos, siempre que la operación no se hiciese con el consentimiento de ellos". ${ }^{62}$ Vemos entonces que el número de estos "rebuscadores de residuos" callejeros no debía ser desdeñable si constituían, como deja entrever esa intervención, una competencia para los ingresos de los contratistas y de la municipalidad. Algo similar se observa en 1880 , cuando en la memoria municipal se menciona la necesidad de reemplazar la diversidad de cestos, cajones y baldes que utilizaban los vecinos porteños para sacar sus desechos a la vereda, $\mathrm{y}$ sustituirlos por "un gran balde cubierto con una pesada piedra o chapa de hierro". ${ }^{33}$ La justificación, una vez más, responsabilizaba a los rebuscadores

60 No podremos extendernos aquí en este punto, pero resta analizar en profundidad esta relación. Sobre la construcción "racial” de la Argentina véase Ezequiel Adamovsky, "El color de la nación argentina. Conflictos y negociaciones por la definición de un ethnos nacional, de la crisis al Bicentenario", Jahrbuch für Geschichte Lateinamerikas, 49, 1 (2012/12): 343-364.

61 Memoria Municipal, 1877: 280.

62 Ibíd.

63 Memoria Municipal, 1880. 
de residuos: con los cajones debidamente cerrados "las basuras llegarían a su destino tal como son arrojadas por las familias, sin que les hayan sacado los huesos y otras materias que constituyen su mayor valor y por ese motivo dichas basuras producirían mayor renta". ${ }^{64}$ Se llegaba incluso a recomendar que los baldes llevaran inscripta la dirección de la casa a la que pertenecían para evitar su robo. ${ }^{65}$

\section{Caracterizaciones de los rebuscadores de residuos}

Las investigaciones sobre las y los recuperadores de residuos de nuestro siglo XXI han mostrado que muchos de ellos se definen como "trabajadores" e incluso han comenzado procesos colectivos de organización para mejorar sus condiciones laborales y modificar su imagen social. Pero estas investigaciones cuentan con la posibilidad de remitirse a la toma de posición de los propios recuperadores (a su “voz"), posibilidad que no tenemos cuando utilizamos fuentes históricas. Es sabido que la palabra de los sectores populares tiende a quedar por fuera de los registros históricos.

No es de extrañar entonces que los testimonios y crónicas que nos permiten caracterizar a la población que se dedicaba a la recuperación de residuos a fines del siglo XIX provengan de las fuentes municipales y policiales, la prensa "burguesa”, las crónicas de viajeros, los médicos higienistas, obras literarias, entre otras; es decir, mediadas. En todas ellas, hay un marcado extrañamiento respecto de ese grupo social que se está describiendo. Extrañamiento que se advierte en la ambivalencia entre el rechazo y cierta atracción por quien se percibe como diferente. Los "rebuscadores" o "raneros" aparecen desde estas miradas como extranjeros en el sentido simmeliano del término, es decir, como aquel que se encuentra en el horizonte espacial de un grupo dado, por lo que es parte del grupo, pero su integración se produce a través de su exclusión. ${ }^{66} \mathrm{El}$ extranjero de Simmel da cuenta de una figura ambigua entre la vinculación y no vinculación al espacio y al grupo social de referencia. Esa extranjería, por la que mientras se los reconoce como parte del conjunto social se lo ubica "afuera y enfrente", se observa una y otra vez en las crónicas que han registrado la vida en el "barrio de las Ranas". El propio término "raneros" que designaba a sus habitantes -aunque no iba dirigido con exclusividad a los recuperadores sino a todos quienes habitaban el barrio-, los ubicaba más cerca de la animalidad que del mundo humano. Ese es quizás uno de los rasgos más salientes de las crónicas: la insistente

64. Memoria Municipal, 1880: 508.

65 Ibíd.

${ }_{66}$ George Simmel, “Digressions sur l'étranger”, en L'École de Chicago. Naissance de l'écologie urbaine, comp. Yves Grafmeyer y Isaac Joseph (París: Champs Flammarion, 1979). 
comparación con todo tipo de animales, fundamentalmente, animales despreciados y asociados al contagio y transmisión de enfermedades: moscas, ratas, gusanos, cerdos, perros salvajes, entre otros. De acuerdo al informe de "expertos" de 1904,

“[en la Quema] se permite que más de 600 seres humanos, mujeres y niños, desempeñen la ocupación de remover las basuras en putrefacción, en busca de alimentos y lo que es más sarcástico como medio de buscarse la vida en promiscuidad con 1500 cerdos, otros tantos perros y millares de ratones que tienen la misma ocupación, el mismo régimen de vida que las mujeres y los niños mencionados. ${ }^{67}$

Quizás uno de los ejemplos más elocuentes de esa extranjeridad, que ubica al barrio y a quienes lo habitan como un submundo marginal, es una crónica publicada en la revista $P B T$ en $1907 .{ }^{68} \mathrm{El}$ relato comienza con el momento en el que los cronistas se introducen en el barrio y dice así: “[Dirigiéndose al comisario que controlaba el lugar] Quisiéramos visitar el barrio de las Ranas, y hemos venido a rogarle nos haga el favor de concedernos un agente para que nos oriente y nos proteja. No crea usted que tenemos miedo, pero...". Y luego, remitiendo a la imagen de una vida social completamente ajena al entramado societal en el que se inserta, como si se tratara de otro país, continúan los cronistas: "Henos, pues, en el país de los 'turros', ó sea en el barrio de las Ranas", mientras que el comisario que los acompañaba lo define como "el viceversa del Municipio". Así, al realizar el recorrido los cronistas no hacen sino confirmar las impresiones (¿prejuicios?) con las que habían llegaron: "se percibe, desde el primer momento, una como á modo de [sic] sensación de delito y de crápula de pillaje y de ocultación". ${ }^{69}$

Pocos años más tarde, en 1910, la ficción teatral tomó a este barrio como escenario. El entonces reconocido dramaturgo Enrique García Velloso estrenó en Buenos Aires la obra En el Barrio de las Ranas. Cuando la obra fue reeditada en 1985, Raúl Castagnino escribió en el prólogo tratando de ubicar histórica y geográficamente al lector: "Escondrijo de delincuentes y criminales, de toda suerte de desheredados de la fortuna; vaciadero y quema de basuras, desperdicios e inmundicias, los desechos humanos que allí buscaban refugio vivían en hacinadas casillas de latas y madera, en promiscua confusión de prostíbulos infames y explotación, de malandraje y depravación”.70 Según Castagnino, a pesar del evidente carácter ficcional de la pieza, ésta fue vivida por el público de la época como una forma de conocer

67 Tratamiento y eliminación, 31.

68 PBT, enero de 1907.

69 Ibíd.

70 Raúl Castagnino, "En el Barrio de las Ranas, de Enrique García Velloso (Estudio preliminar)”, en Enrique García Velloso, En el Barrio de las Ranas (Buenos Aires: Instituto Ricardo Rojas, 1985). 
ese "submundo", porque "entre la gente honesta, esa que sólo por las noticias policiales sabía de hábitos y malandanzas de los malhechores, se había despertado una especie de curiosidad por 'ver' el Barrio de las Ranas, al menos en el escenario, sin los riesgos de transitar la zona vedada”. ${ }^{71} \mathrm{Y}$ si bien la obra no tiene entre sus personajes de la "mala vida" a recuperadores de residuos, sabemos que estos eran una porción muy considerable de quienes habitaban el barrio.

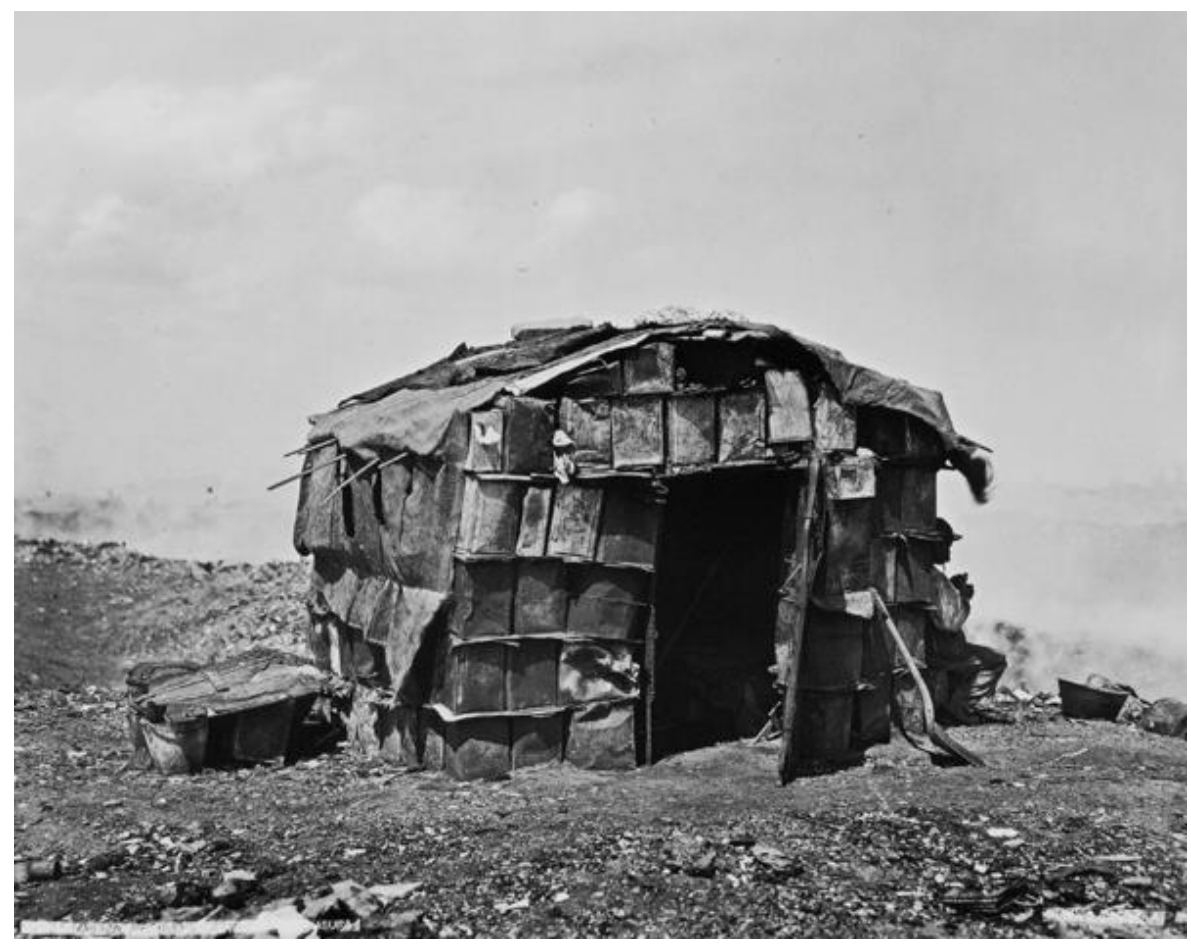

Habitación en la Quema. Fotografía del norteamericano H. Grant Olds.

Tampoco el viajante francés Jules Huret pudo resistirse a dejar testimonio de este particular barrio, al que describió como una muestra del carácter inconcluso del sendero de prosperidad que Buenos Aires había iniciado. Lo describe con ironía como "el estilo lata de petróleo", un "vestigio persistente y tenaz del Buenos Aires de antaño", ${ }^{2}$ en el que "no se ven (...) más que casas construidas con hojalata, cuyas paredes, tejados, puertas y columnas resplandecen al sol", y en el que "el trust del Standard Oil, presidido por

71 Ibíd.

72 Jules Huret, De Buenos Aires al Gran Chaco (Madrid: Hyspamérica, 1988 [1911]), 55 . 
Míster Rockefeller, ha proporcionado casi todos los materiales". ${ }^{73}$ Pero es interesante hacer notar que estas construcciones, según su propia descripción, no estaban tan alejadas de las de algunos suburbios obreros, en donde "hay otras construidas con latón estampado, imitando la pizarra, que dan la impresión de un campamento 'nómada' de colonos. Todavía las hay más humildes, construidas con planchas pintarrajeadas de verde ó de rosa vivo por sus mismos dueños y que se parecen á cabañas de gitanos ó bohemios dispuestos á dejar el lugar en cuanto sea preciso". ${ }^{74}$ Sin embargo, allí terminaban para el ilustre visitante las similitudes entre suburbios obreros y este barrio, puesto que las diferencias prevalecían cuando se trataba de dar cuenta de la valoración de sus habitantes. En su descripción de la "mala vida" congregada allí, Huret refería a la heterogeneidad racial y de nacionalidad, y a la presencia de mujeres (y mujeres negras en particular): "Estos palacios y casuchas están habitados por algunas negras, mestizos, europeos e indígenas". 75

La mujer "ranera" se describe en algunos registros con particular desprecio y sarcasmo. La revista de humor político PBT describía a una mujer del barrio como "una especie de marimacho roñoso y ebrio (...). Se le conoce por el nombre de la china Barrea, y es uno de esos tipos que sugieren las más graves dudas acerca de la existencia de un sexo bello por antonomasia”. ${ }^{76} \mathrm{La}$ nota estaba acompañada de dos fotos de mujeres con las siguientes inscripciones: "dos bellezas raneras", en el marco de una descripción que no deja dudas sobre su tono irónico, y "Dúo de bombilla ó rana y renacuajo" (en referencia a una madre y una hija del barrio de las Ranas). Otra nota de la revista titulada "La cuestión sucia", que relataba una visita del intendente Alvear a la Quema, decía: "la población no le fue menos repelente que el paisaje (...) al elemento femenino lo halló antidecorativo y despojado de seducciones", mientras su apreciación de los varones no se quedaba atrás: "Los hombres de la comarca, melenudos y retobados, le parecieron sencillamente feos". 77

\footnotetext{
73 Ibíd.

74 Ibíd.

75 Ibíd., 55. El subrayado es del original.

76 PBT, 1907, "El barrio de las Ranas".

77 PBT, 1907, "La cuestión sucia".
} 

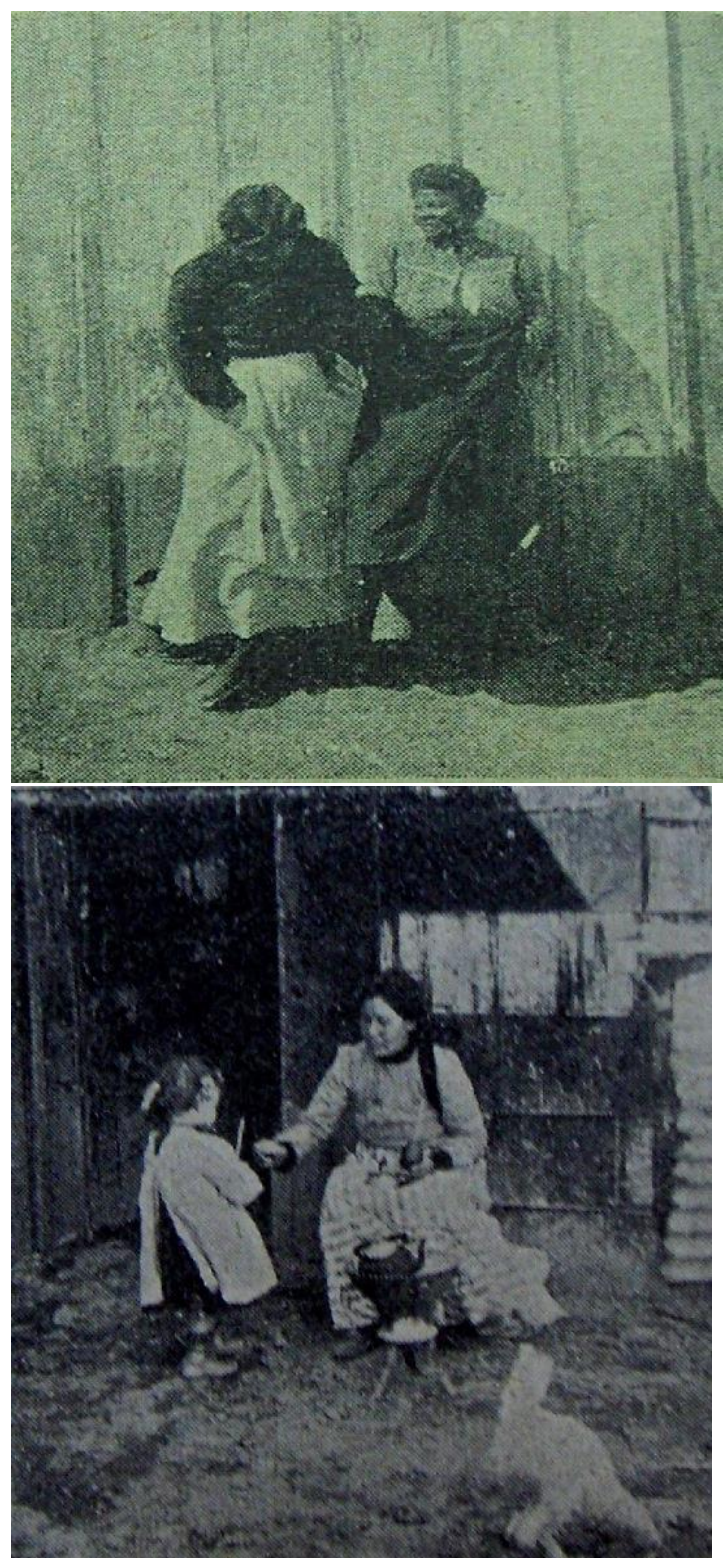

“Dos bellezas raneras” y “Dúo de bombilla o rana y renacuajo”, en PBT, 1907.

Gabriela Laperrière de Coni, periodista, militante socialista e inspectora adhonorem de la municipalidad, dejó una de las miradas más originales de las y los trabajadores de la Quema. ${ }^{78}$ No se trata de que esa extranjeridad no estuviese presente, pero incorpora una dimensión de empatía y alude a la 
desigualdad como trasfondo. En su relato sobre la visita que realizó en su rol de inspectora describe a un heterogéneo grupo de personas entre los que se encuentran "niños, peones, muchachas bonitas" que "inclinados y apiñados sobre el tumbado carro, revisan febrilmente los residuos, [y] apartan de ellos los huesos, vidrios, papeles, trapos, legumbres" y "en un lienzo extendido depositan cuidadosamente la comida". ${ }^{79}$ Los materiales útiles, explica, eran entregados al concesionario como condición para quedarse con los alimentos:

Un niño se va cargado con una lata de huesos y un atadito de comida. (...). Entrega primero los huesos en la fábrica de los concesionarios, pues no se le permite aprovechar la comida sin esta compensación. Para tener derecho a media bolsa de comida, que sirve en parte para alimentar cerdos, debe entregarse una lata de huesos. ${ }^{80}$

Nada se dice acerca del destino del resto de los objetos recogidos que se mencionan en la misma nota: vidrios, papeles, trapos, entre otros.

Todos estos relatos se ubican temporalmente entre los últimos años del siglo XIX y la primera década del XX, momento en el que la "cuestión higiénica" había ganado centralidad luego de los brotes epidémicos y la mirada negativa sobre los desechos se había intensificado. ${ }^{81} \mathrm{El}$ elemento común es la ausencia de cualquier conexión entre la recuperación de residuos y la idea de una actividad productiva, proveedora de materias primas industriales o agrarias y fuente de ingreso no sólo para los propios recuperadores sino también para otros actores privados y municipales. Se enfatizaba, en cambio, la satisfacción de necesidades vitales inmediatas, al mencionar la recuperación de alimentos descartados o de materiales para la construcción de las casas. Un ejemplo interesante de esta forma de desvinculación es la siguiente crónica de $L a$ Prensa de 1907:82

Abundan en esa aglomeración de focos de infección las casas de comercio [de materiales recuperados]. De éstas no hay menos de cuarenta, cada una en su especialidad. Las hay que compran trapos, latas, vidrios, hierro, huesos, legumbres, carne, cueros, papel, maderas; en fin, de todo cuanto puede representar algún valor, por exiguo que sea. Allí se negocia lo que traen los buscadores, en pequeñas carretillas de mano, construidas con tablitas y herrajes usados. (...). Desde las seis de la mañana hasta las últimas horas de la tarde se ve una caravana continua de esos vehículos, algunos tirados por perros y otros por carneros. Se detienen en la casa de compra del ramo á que pertenece el contenido de cada carretilla; y allí, por pocos centavos, 5 ó 10, entregan los buscadores todo el producto del día. ${ }^{83}$

\footnotetext{
${ }^{79}$ Ibid.

${ }^{80}$ Ibíd. El subrayado es del original.

${ }^{81}$ Dimarco, "De lo patógeno".

${ }^{82}$ La Prensa, 10/5/1903.

${ }^{83}$ Ibíd.
} 
Como vemos, allí se describía con detalle el importante desarrollo que habían tenido los comercios vinculados a la compra y venta de residuos recuperados. Aun así, después de dar cuenta del importante circuito comercial generado en torno a esa actividad, decía que había "no menos de dos mil personas (...) que no viven de otra cosa más que de lo que recogen en los montones de basura" 84 y "grupos de ocho ó diez personas (...) sentadas tranquilamente sobre los montones de residuos y eligiendo, con toda calma, lo que más les agrada para la alimentación", "esos desgraciados se abalanzan sobre los montones de basura y van buscando todo lo que sea comestible" ${ }^{85}$ En otras palabras, ese importante comercio de materias primas y la actividad de los "buscadores" (como los menciona la nota) no se articulaban en torno a la idea de trabajo productivo.

\section{La imposible profesionalización de los recuperadores de residuos a fines del siglo XIX}

Vimos hasta aquí que, por un lado, la práctica de "extracción de residuos entre las basuras" estaba arraigada y era rentable para diferentes actores. Se requería entonces de peones dispuestos a realizar esa tarea que, en algunos casos, formaba parte de las ocupaciones de la limpieza e higiene urbana. Pero, por otro lado, sobre las y los recuperadores de residuos pesaba una fuerte condena moral: independientemente del valor económico de su tarea, y de su función en el desarrollo productivo con la provisión de materias primas, pesaba sobre ellos una mirada desvalorizante. Podríamos preguntarnos si el reconocimiento de la actividad variaba en los casos de quienes la llevaban adelante bajo contrato en la Quema en relación con quienes lo hacían de forma independiente o en la vía pública, en una suerte de jerarquización de las ocupaciones del "trabajo sucio". ${ }^{86}$ Por momentos, como vimos, los documentos parecen mostrar que efectivamente era así. No obstante, vimos también que en la práctica de las y los recuperadores esas distinciones eran difusas. Se podía trabajar durante el día para el concesionario y terminada la jornada permanecer en la Quema para recuperar y vender por cuenta propia. También se aprovechaba el horario de trabajo para, en el mismo proceso de clasificación, separar algunos elementos para uso privado o para venderlos luego. Esta última práctica estaba tan asentada que había personal encargado de revisar a los clasificadores una vez terminada la tarea (los "revisadores") para evitar que se llevaran "joyas y otros objetos de valor". ${ }^{87}$

\footnotetext{
${ }^{84}$ Ibid., 4.

${ }^{85}$ Ibíd., el subrayado es nuestro.

${ }^{86}$ Lhuilier, Le 'sale boulot'...

${ }^{87}$ Caras y Caretas, 1905.
} 
Mencionamos también que el uso que se le daba a lo recuperado -un uso directo como alimento o para la venta- podía usarse como argumento para posicionar a la actividad como trabajo o no-trabajo. Sin embargo, también en este caso la distinción carece de sentido en la experiencia concreta de estos trabajadores. Con frecuencia, quienes recuperaban materiales que entraban al circuito productivo no despreciaban restos de comida, ropa u otros elementos que eran utilizados por el mismo clasificador o revendidos en el barrio. ${ }^{88} \mathrm{En}$ La Prensa se relataba la siguiente situación: " ${ }_{\mathrm{C} C}$ Cuánto le cuesta el tacho de pan?] Cinco centavos, y es fresquito; me lo trajo el negrito Casimiro, el más vivo de todos los buscadores", y agrega el cronista: "Con esto nos quería decir que ese pan procedía de la quema, y que cada trozo había sido recogido de entre un montón de residuos de los que descargan los carros de la limpieza pública”. 89

Según el informe antes citado de la Comisión de expertos, incluso los basureros entraban en este circuito. Allí se mencionaba que las casillas del barrio de las Ranas se encontraban atestadas de alimentos obtenidos de los desechos ("sartas de gallinas, quesos, latas de conserva en mal estado" 90 ) pero se ocupaba de aclarar que no todos provenían de la Quema: "algunos de estos elementos procedentes de las casas y restaurants, han sido apartados ya por el basurero del resto de la basura que conduce en su carro; trayéndolos envueltos en papeles que ha sacado de la misma y así acondicionados son colocados en una bolsa y depositados sobre las basuras que conduce hasta llegar a su destino, de donde los lleva a su casa para alimentarse con ellos". ${ }^{91}$ En esa misma línea, Prignano menciona la existencia de peones que acompañaban a los basureros en el trayecto con la función de entrar en las casas a buscar los desechos cuando aún no se dejaban en las veredas o zaguanes. ${ }^{92}$ Los peones, menciona este autor, se convirtieron en un problema para los contratistas porque aprovechaban el trayecto en el carro para ir separando de la basura diferentes materiales que luego vendían por su cuenta o utilizaban directamente para su subsistencia.

Uno de los pocos testimonios de la época que se aleja de los mencionados, en tanto reconoce a los recuperadores de residuos como trabajadores, proviene de los periódicos socialistas. La Vanguardia dedicó algunas breves notas a la situación gremial de los recuperadores y a la necesidad de pelear por mejores salarios y condiciones laborales. Denunciando esas condiciones, explicaban que los empleados de la Quema trabajaban por un jornal y como parte de sus tareas se les exigía "juntar una lata de pan, una de corcho, un canasto y una

88 La Nación, 4/05/1911.

89 La Prensa, 10/05/1903.

90 Tratamiento y eliminación, 27.

$91 \quad$ Ibíd., 28.

92 Prignano, Crónica de la basura... 
bolsa de huesos"; de no hacerlo, "por falta de tiempo, de huesos, corchos ó pan", se les cobraba dos pesos de multa por cada cosa. ${ }^{93}$ Frente a ello, en la sección "movimiento gremial" del órgano de difusión del Partido Socialista, decían: "los trabajadores de la Quema nos envían el siguiente manifiesto, demasiado elocuente, para que todos puedan darse cuenta de cómo son tratados dichos asalariados". ${ }^{44} \mathrm{Y}$ enunciaban los reclamos de los peones en huelga: horario de 9 horas (en lugar del de 12 a 14 que realizaban); abolición de tareas asignadas de antemano; abolición de multas; salario de $\$ 2.50$ por día (en lugar del \$1.50 que recibían).

En otra nota, el socialista Enrique Dickmann describía la actividad de recuperación de residuos en su sentido productivo: "En esta división es donde se descarga toda la basura que viene de la ciudad, y se la pasa por un análisis macro y microscópico, para que no se pierda ningún huesito, ningún trapito. De todo se saca beneficio y de todo se hace riqueza". ${ }^{55}$ Pero incluso a pesar de este reconocimiento del valor económico-productivo de la actividad, las descripciones de las y los recuperadores no están muy alejadas de los relatos de su época: "Asquerosos, harapientos, semidesnudos, las mujeres junto con los hombres, se hunden en ese montón de inmundicias, y automáticamente levantan las bolsas cargadas de huesos y trapos, y las transportan á otro lugar, de donde pasan directamente a la fábrica" ${ }^{96} \mathrm{El}$ discurso alternizante también se hace aquí presente: "Allí habita una raza completamente diferente de la de nosotros. Mujeres desfiguradas, flacas, enfermas, asquerosas y harapientas; niños parecidos más bien a monos que a hombres". ${ }^{97}$ Sin embargo, a diferencia de lo visto anteriormente, Dickmann asocia esas formas laborales a las condiciones más generales de la explotación capitalista sufrida por los obreros, lo que le da pie para plantear la necesidad de que este sector de los trabajadores también se organice, abrace la causa socialista, y luche por condiciones más dignas. En esa línea, desde el partido se buscó un acercamiento a este gremio en un intento por sumarlos a sus filas. Desde la agrupación Carlos Marx, por ejemplo, se brindaron conferencias en el predio mismo de la Quema en apoyo "a los peones municipales de las basuras", en la que hicieron uso de la palabra figuras claves del socialismo como Patroni, Dickmann e Ingenieros. ${ }^{98}$ Los peones, de acuerdo al periódico, escucharon “con marcadas muestras de aprobación”. Algunos meses después, desde La

$93 \quad$ La Vanguardia, 6/3/1897.

94. Ibíd.

95 La Vanguardia, 15/5/1897.

96 Ibíd.

97 Ibíd.

98 La Vanguardia, 12/6/1897. Cinco meses más tarde se organizó una nueva conferencia en el mismo lugar, La Vanguardia, 18/9/1897. 
Vanguardia se denunciaba que dos peones habían sido despedidos de la Quema por afiliarse al Partido Socialista.
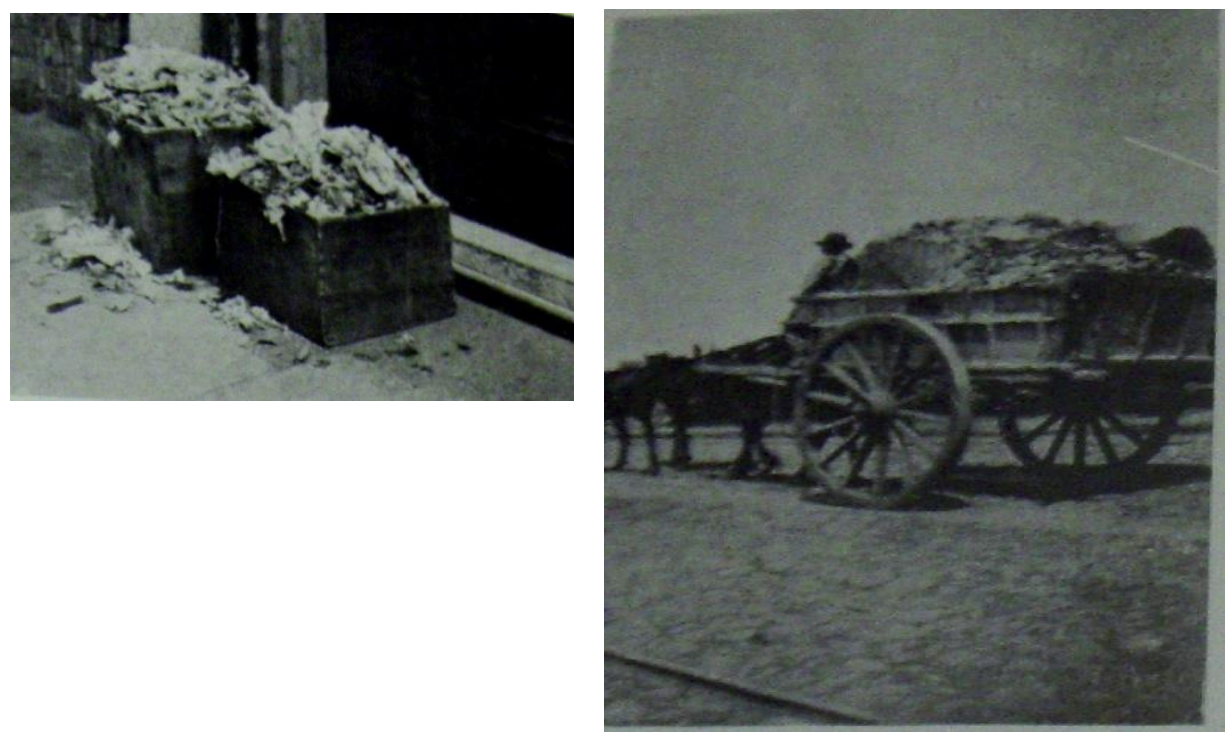

Recipientes domésticos de desechos y carro de recolección. Informe Municipal, 1904.

Vemos entonces que hacia finales de siglo la recuperación de residuos se encontraba en pleno desarrollo, pero su estatus como trabajo no estaba claro. Las condiciones laborales de quienes se ocupaban de esa tarea eran, sin duda, muy deficientes; pero también lo eran las de muchas otras ocupaciones en esos años finiseculares. Más aún las del resto de las ocupaciones de la higiene y la limpieza pública. Todas ellas se encontraban en lo más bajo de la jerarquía ocupacional. Siguiendo a Lhuilier, podríamos distinguir procesos de jerarquización interna a este sector de ocupaciones de la limpieza pública (incluidos los recuperadores de desechos) en función de las gradaciones de cercanía a la basura que la actividad requiere. Todas estas ocupaciones tienen, en mayor o en menor medida, cierta proximidad con la suciedad y los desechos. Los basureros debían volcar los desechos de los recipientes domiciliarios (por lo general abiertos y desbordantes) depositados en las veredas a su propio recipiente y de allí al carro, de modo que tenían un contacto muy estrecho con los desechos como puede observarse en las fotografías de la época. Durante el traslado, el contacto del carrero y/o basurero con los detritus no era menor, como se desprende de esta carta presentada por la Unión Industrial Argentina a Alvear:

El estómago más fuerte decae dominado por el pestilente olor que despiden los vehículos cargados de basura en fermentación, que siguen sin cesar en todo lo largo de la calle. Esos carros inmundos con acompañamiento de 
nubes de moscas, deberían estacionarse en frente del palacio del Sr. Intendente para que supiese lo que bueno, y tuviese un poco más de lástima de los vecinos y transeúntes de la calle principal de Buenos Aires. ${ }^{99}$

No muy distinta era la experiencia de los encargados de manejar el "tren de las basuras”, puesto que los vagones iban abiertos, emanando hedores y dejando caer los desecho durante el recorrido. Más claro aún en el caso de los parveros, quienes valiéndose únicamente de rastrillos debían controlar el proceso de cremación parados sobre las basuras ardientes.

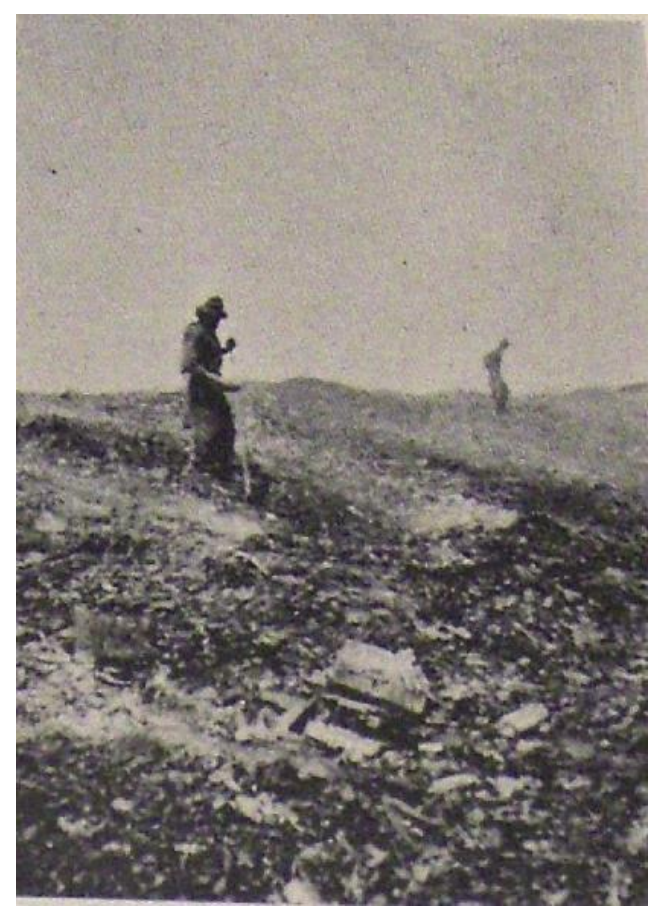

Empleados en pleno proceso de incineración en la Quema. Informe Municipal, 1904.

Sin embargo, los clasificadores de residuos sumaban a esas condiciones laborales un elemento que los distinguía del resto y los volvía particularmente proclives al rechazo social: no se trataba solamente de la cercanía con los desechos sino de su manipulación. Y algo más: si a medida que nos acercamos al siglo XX, siguiendo las teorías higienistas, las políticas públicas tendieron cada vez más a alejar los desechos de la vida urbana, la

99 Unión Industrial Argentina, 1/2/1885, citado en Cortese. 
actividad de los recuperadores consistía justamente en el proceso inverso, la reincorporación a la vida social de aquello que había sido descartado.

En efecto, las y los clasificadores de residuos no solo cargaban con la proximidad a los desechos (lo que compartían con otros trabajadores de esta área) sino que su tarea requería para ser efectiva de su manipulación. Este contacto estrecho, sin mediaciones de ningún tipo, comenzó a hacerse más problemático a medida que, entrando al siglo XX, la mirada higienista focalizó en los desechos como un problema sanitario. Acompañando ese proceso, junto a la extensión de las relaciones salariales, la mayor parte de los trabajadores de la limpieza pública se fueron profesionalizando y mejorando, al menos en parte, sus condiciones laborales. Muchos de esos cambios tuvieron que ver con formas de evitar el contacto y la cercanía con los desechos, apoyados en la incorporación de herramientas y ropa de trabajo más apropiadas y, en algunos casos, en la mecanización progresiva de las operaciones de limpieza y tratamiento de los desechos. En esta línea, los expertos recomendaban, siguiendo el ejemplo inglés, la implementación de carros cerrados herméticamente de modo que el distanciamiento con los desechos fuese total. 100

Finalmente, a comienzos del siglo XX, la comisión de expertos mencionada anteriormente concluyó, luego de un estudio exhaustivo y comparativo con otras ciudades del mundo, en la necesidad de terminar con lo que llamaba "un sistema primitivo", en referencia a la Quema. Propuso en su lugar la instalación de hornos modernos de incineración. Ese informe fue particularmente duro con el trabajo de los clasificadores de residuos, y determinó que la actividad debía cesar por completo, en tanto la consideraban un riesgo para los propios recuperadores y para la salud pública. En consecuencia, en 1908 se terminó con la actividad de "extracción de residuos de las basuras" y se dio inicio a lo que sería la larga etapa de la eliminación radical de los desechos sin distinción: "por el presente contrato se suprime el derecho acordado por el anterior contratista, de explotar directamente los metales, botellas y vidrios debiendo estos componentes de la basura ser sometidos como los otros a la acción directa del fuego". ${ }^{101}$ En 1911, la Intendencia, con el apoyo de la Policía y de cuadrillas especiales de la Administración General de Limpieza, "inspirada en el propósito de saneamiento del conocido 'Barrio de la Quema”" desalojó a sus habitantes y demolió "todas las casillas de madera que formaban el 'Pueblo de las Ranas'

100 Ibid., 220.

101 Memoria Municipal, 1908: 197. 
y las construcciones de lata levantadas a inmediaciones de la Quema”. ${ }^{102}$ Roccatagliata menciona verdaderas batallas entre los chiffoniers y la policía. ${ }^{103}$

Los recuperadores de residuos no desaparecieron del todo con esas medidas y la clasificación de residuos para la venta continuó siendo una alternativa de subsistencia para los sectores más vulnerables de la sociedad. Pero luego de esos primeros intentos de organización del gremio como parte de la clase obrera, durante mucho tiempo quedaron asociados al no-trabajo, a la mendicidad y la vagancia -evocada por el término “cirujeo"- más que a una forma legítima y productiva de trabajo.

\section{Conclusiones}

En estas páginas nos hemos ocupado del análisis del período de mayor desarrollo de la práctica de clasificación de residuos en la ciudad de Buenos Aires. En un ejercicio socio-histórico, nos sumergimos en una etapa en la que el mercado de trabajo recién se estaba constituyendo con sus rasgos "modernos" y comenzaba a conformarse un servicio público de limpieza e higiene urbana con sus trabajadores específicos. En ese momento, la clasificación de residuos era una práctica en boga, en la que distintos actores socioeconómicos encontraban beneficios y que daba empleo a una franja de la población. Así, en ese mercado de trabajo en expansión en el que surgían y se profesionalizaban nuevas ocupaciones laborales, la clasificación de residuos aparecía como una más, entre otras, de esas múltiples y diversas actividades de finales del siglo XIX. Esa práctica se llevaba delante de diversas maneras: en la Quema, en las calles, puerta a puerta; bajo contrato, independiente, etc.

Vimos que, si bien las distintas ocupaciones laborales vinculadas a la limpieza y la gestión de los desechos ocupaban una posición relegada en la jerarquía ocupacional, en gran medida como consecuencia de lo abyecto de su objeto de trabajo, la cercanía mucho mayor de los clasificadores de residuos con los desechos -la manipulación como elemento central de la labor- los ubicó en un lugar particularmente desvalorizado, que se volvió problemático en el marco de las preocupaciones epidémicas.

Así, mientras que algunas de las ocupaciones de la limpieza y la gestión de desechos se fueron profesionalizando (los barrenderos y basureros, por ejemplo), entrando progresivamente en marcos regulatorios, seguridad social, sindicalización, entre otros elementos clave en ese proceso de reconocimiento de su labor, la clasificación de residuos siguió el camino

102 Memoria Municipal, 1911: 264.

103 Atilio Roccatagliata, "Los "chiffonnier" (Los traperos)", (Tesis doctoral, Facultad de Medicina - UBA, 1919). 
inverso. En efecto, si en esos años de fin de siglo XIX era una actividad pujante, en pleno desarrollo, y sus trabajadores habían comenzado a dar los primeros pasos en procesos organizativos y de lucha en busca de mejoras salariales y de condiciones laborales, ese proceso quedó truncado cuando los temores al contagio dieron por finalizadas las prácticas de recuperación de residuos y comenzaron, en su lugar, las acciones tendientes a la eliminación radical (y sin distinción) de la totalidad de los desechos producidos por la ciudad, con la implementación de métodos que garantizaran el distanciamiento. Ello no implicó, no obstante, la desaparición de la actividad de recuperación de residuos y de las y los recuperadores, pero sí la imposibilidad de ser reconocida socialmente como un trabajo legítimo. Así también, los términos "rebuscadores de residuos", "cateadores", "peones de la clasificación", con los que los encontramos en los registros que han quedado de aquellos años, pasaron a ser identificados como "cirujas", término peyorativo ligado a la mendicidad y la vagancia. ${ }^{104}$

Desde hace unas pocas décadas, las preocupaciones ambientalistas (a diferencia de las preocupaciones 'higienistas' de fin de siglo XIX) le están dando una nueva oportunidad a esta actividad laboral y han comenzado a modificar -en parte- esa imagen social negativa. Las nuevas organizaciones de recuperadores de residuos, algunas muy importantes como la Federación Argentina de Cartoneros, Carreros y Recicladores (FACCYR) que nuclea a más de 100 cooperativas y 15.000 cartoneros y cartoneras de todo el país, parecen estar retomando algunas de las luchas de aquellos antiguos "rebuscadores" que durante más de un siglo quedaron inconclusas. Ser reconocidos como trabajadores (por el Estado y la ciudadanía en general pero también por el resto de los trabajadores), gozar de un salario digno, y mejoramiento de las condiciones laborales son algunas de esas demandas de ayer y de hoy.

${ }^{104}$ En su diccionario de lunfardo, José Gobello explica que una de las definiciones de "ciruja” es "holgazán, vago". José Gobello, Nuevo diccionario lunfardo (Buenos Aires: Corregidor, 1994). 
Title: "Waste Pickers" at the End of the Nineteenth Century: History of an Unfinished Professionalization (Buenos Aires, 1870-1911)

Abstract: This article examines the period of greatest development of the practice of waste sorting in Buenos Aires, Argentina, at the end of the nineteenth century. It aims to address the ambivalent way in which this practice was socially represented at a time when its economic value was not in doubt. In particular, it explores the difficulties encountered by these workers to become professionalized until they were displaced from socially recognized occupations at the beginning of the twentieth century. In so doing, it examines some interpretations regarding the persistence of a stigmatizing image of waste pickers, an image that is currently in full symbolic dispute due to environmental concerns. The article draws upon different sources, such as municipal memoirs and magazines, press, police records, plays, travelers' diaries, photographs, and engravings.

Keywords: waste pickers, work, garbage, waste, Buenos Aires.

Titulo: "Catadores" no final do século XIX: história de uma profissionalização inacabada (Buenos Aires, 1870-1911)

Este artigo examina o período de maior desenvolvimento da prática de classificação de resíduos em Buenos Aires, Argentina, no final do século XIX. Visa abordar a forma ambivalente em que esta prática foi socialmente representada numa época em que seu valor econômico não estava em dúvida. Em particular, explora as dificuldades que esses trabalhadores encontraram para se profissionalizar até serem deslocados de ocupações socialmente reconhecidas no início do século XX. Ao fazê-lo, examina algumas interpretações a respeito da persistência de uma imagem estigmatizante dos catadores, uma imagem que atualmente está em plena disputa simbólica devido a preocupações ambientais. $\mathrm{O}$ artigo se baseia em diferentes fontes, tais como memórias e revistas municipais, imprensa, registros policiais, peças de teatro, diários de viagem, fotografias e gravuras.

Palavras-chave: catadores, trabalho, lixo, resíduos, Buenos Aires 